Vol. 1, 1-16, 2014

www.aspbs.com/jnd

\title{
Prevention of Bacterial Infections Using Encapsulated Phytophenolic Actives
}

\author{
Angelique Montagu ${ }^{1,2,3, *}$, Patrick Saulnier ${ }^{1,2}$, Elisabeth Rossines ${ }^{3}$, and Marie-Laure Joly Guillou ${ }^{4}$ \\ ${ }^{1}$ LUNAM Université, F-49933 Angers, France \\ 2 INSERM U1066, Micro et Nanomédecines Biomimétiques, IBS-CHU, 4 Rue Larrey, F-49933 Angers, France \\ ${ }^{3}$ Eydopharma, 5 allée des Grandes Bruyères, F-41200 Romorantin-Lanthenay, France \\ ${ }^{4}$ Laboratoire de Microbiologie UPRESEA 3142, CHU Angers, 4 Rue Larrey, 49033 Angers, France
}

\begin{abstract}
The recent overuse of antibiotics has led to the emergence of multidrug-resistant bacteria (MRB) responsible for severe infections, which are often difficult or impossible to treat. In the world of infectious diseases, the lack of development of new antibacterial molecules by the pharmaceutical industry is a major problem. Today, the number of new drugs able to treat Gram-negative MRB infections is significantly limited. It is therefore important to find new therapeutic approaches that are effective but limit the emergence of bacterial resistance. Medicinal plants containing essential oils constitute a potentially large source of antibacterial molecules that can be used to treat MRB infections. Essential oils, which primarily consist of phenolic compounds, have been demonstrated to have antibacterial effects against a wide variety of microorganisms. However, these molecules exhibit poor solubility in water and are biologically unstable. In addition, these molecules tend to bind to food constituents, resulting in decreased bioavailability and antimicrobial activity. To overcome these challenges, essential oils can be encapsulated within nanoparticles to enhance their solubility in aqueous media and to increase their antibacterial activity by facilitating contact with bacterial cells. The high antibacterial effectiveness of several delivery systems, including emulsions, liposomes and nanoparticles, indicates the potential of encapsulated phenols. The anti-infective potential of essential oils, combined with various technologies from nanomedicine, provides a new hope in the fight against infectious diseases.
\end{abstract}

KEYWORDS: Multiresistant Bacterial Infections, Essential Oils, Phenols, Delivery System, Nanoparticles.

\section{CONTENTS}

\section{Introduction .}

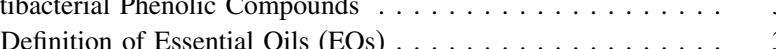

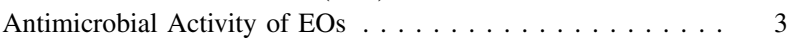

Antibacterial Actions of Phenolic Compounds . . . . . . . . 3

Encapsulation of Phenolic Compounds Extracted from EOs .... 8

Emulsions and Nanoemulsions . . . . . . . . . . . . 9

Liposomes . . . . . . . . . . . . . . . . . . . . . . . 11

Micelles and Microemulsions . . . . . . . . . . . . . . . . . . . . . . 11

Nanospheres-Nanocapsules . . . . . . . . . . . . . . 12

Novel Phenolic Compounds Delivery System . . . . . . . . . . . . . . . . . . . . . . . . . . .

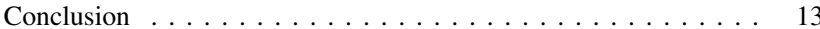

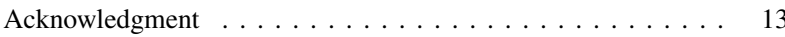

References . . . . . . . . . . . . . . . . . . . . . . 13

\footnotetext{
${ }^{*}$ Author to whom correspondence should be addressed.

Email: angelique.montagu@gmail.com

Received: 26 August 2013

Accepted: 13 January 2014
}

\section{INTRODUCTION}

Since 1945, many antibiotics have been developed, and many of these antibiotics possess a broad activity spectrum. Since the 1960s, the abuse of antibiotics in many areas (e.g., human health, agriculture, and veterinary practice) has led to the emergence of resistant bacteria that have developed or acquired several mechanisms of drug resistance. As a result, some bacteria are now resistant to most of the antibiotics commonly used in clinical settings and are responsible for hospital infections that are difficult to treat. Among MRB strains, multiresistant Acinetobacter baumannii (MRAB), methicillin-resistant Staphylococcus aureus (MRSA) and extended spectrum B-lactamase- or carbapenemase-producing Enterobacteriaceae (ESBLE, CPE) are the most prevalent MRB strains in Europe. ${ }^{1}$ Thirty to $35 \%$ of nosocomial infections are caused by MRB. ${ }^{2}$ The struggle against nosocomial infections is a public health priority because such infections are characterized by high morbidity and mortality rates. ${ }^{3}$ 
According to the World Health Organization (WHO), 1.4 million people suffered from nosocomial infections in 2007. In developed countries, up to $10 \%$ of hospital patients acquire nosocomial infections. In some developing countries, this infection rate can be as high as $25 \%$. According to a 2012 survey conducted in France, $5 \%$ of hospital patients acquired an infection. The bacteria responsible for such infections can quickly adapt and develop several resistance mechanisms, including decreased membrane permeability, bacterial efflux pumps, enzymatic degradation of antibiotics and modification or alteration of the target antibiotic. These mechanisms, which are often acquired through the uptake and integration of foreign genetic material, can transform bacteria into powerful MRBs. ${ }^{4}$ Spurred by the current global prevalence of Gram-positive MRBs, the pharmaceutical industry has
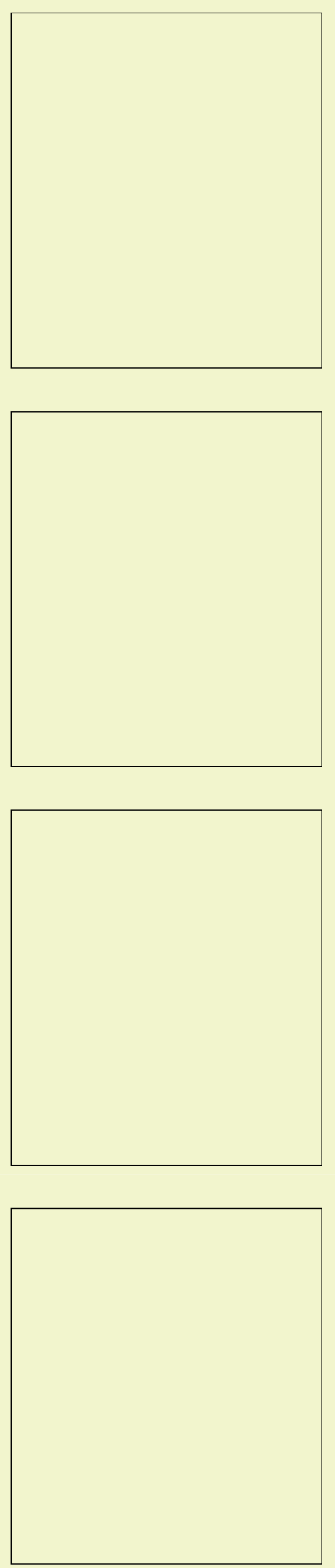

Angelique Montagu

Patrick Saulnier

Elisabeth Rossines

Marie-Laure Joly Guillou 
focused recently on developing new antibiotics that target Gram-positive MRBs such as methicillin-resistant $S$. aureus and glycopeptide-resistant enterococci. In contrast, very little effort is expended on developing new molecules against Gram-negative MRBs. Given the limited number of antibiotics in development as well as the spread of ESBLE and $\mathrm{CPE}$, the discovery of novel antibacterial strategies is a critical endeavor.

Various actives have been explored for antibacterial activity, including silver nanoparticles, ${ }^{5,6}$ gold nanoparticles, ${ }^{7,8}$ zinc nanoparticles ${ }^{9,10}$ and nitric oxide nanoparticles. ${ }^{11,12}$ Until now, natural resources have been poorly explored.

Essential oils (EOs), composed mainly of phenolic compounds, have been shown to have antibacterial properties against a wide variety of microorganisms. However, these molecules possess various lipophilic characteristics that reduce bioavailability. To overcome these challenges, these phenols can be encapsulated within nanoparticles to enhance their solubility in aqueous media.

The objective of this review is to describe various delivery systems such as emulsions, liposomes and nanoparticles and to discuss the possibility of encapsulating phenolic actives using these nanodelivery systems. The anti-infective potential of essential oils, combined with various technologies from nanomedicine, provides a new hope in the fight against infectious diseases.

\section{ANTIBACTERIAL PHENOLIC COMPOUNDS Definition of Essential Oils (EOs)}

Essential oils (EOs) are complex, volatile mixtures of low molecular weight molecules. EOs are synthesized within various plant organs and can contain between 20 to 60 components at various concentrations. ${ }^{13}$ Essential oils are characterized by two or three major components in relatively high concentrations (20-70\%), while the other components are present in trace amounts. For example, carvacrol $(30 \%)$ and thymol $(27 \%)$ are the major components of the EO from Origanum compactum. ${ }^{13}$ The composition of the EO depends on various factors, including the stage of plant development, the organs present and the period and geographical area of harvest. ${ }^{14}$

EOs are secondary plant metabolites synthesized in glandular structures within plant cells ${ }^{15}$ and are known to have strong antibacterial potential. ${ }^{14}$ The biological activity of EOs is mainly due to their chemical composition. EOs can contain both phenols and terpenoids. EOs components induce endogenous protective enzymes and have beneficial regulatory effects on signaling pathways, acting as antioxidants. ${ }^{16}$

The major components of EO can be divided into 2 groups based on the distinct pathways for their biosynthesis: phenylpropanoids and terpenoids. ${ }^{13}$

Terpenoid components derive from a 5-carbon isoprene precursor, isopentenylpyrophosphate (Fig. 1). Terpenoids exist in various forms,including mono-, di-, tri-, hemi-, sesqui-, and tetra-terpenes. Monoterpenes are characterized by two isoprene units $\left(\left(\mathrm{C}_{5} \mathrm{H}_{8}\right)_{2}\right)$ and are the building block for $90 \%$ of all EO molecules, including hydrocarbons, aldehydes, alcohols, esters, ethers, ketones, peroxides and phenols. ${ }^{13}$

Phenolic compounds (phenylpropanoids) derive from aromatic amino acids such as phenylalanine and tyrosine (Fig. 2). Phenolic compounds are composed of aldehydes, methoxy derivatives, methylene dioxy components, phenols and alcohols.

Phenols are characterized by the presence of a hydroxyl group attached to a phenyl ring. Phenolic compounds possess the greatest antibacterial potential, followed by aldehydes, ketones, alcohols and hydrocarbons. ${ }^{15}$

\section{Antimicrobial Activity of EOs}

Various studies have shown that phenols, aldehydes and terpenes mainly target the cytoplasmic cell membrane. Hydrophobic in nature, these compounds affect the unsaturated fatty acid content in the membrane and thus alter the membrane's structure. ${ }^{17,18}$

The presence of phenols (e.g., eugenol, carvacrol, and thymol) and aldehydes (e.g., cinnamaldehyde, perillaldehyde, and citral) in EOs may be responsible for the broad spectrum activity of EOs on microorganisms such as bacteria, fungi, viruses, parasites and insects. ${ }^{13}$

Bacteria can be classified into two groups according to the composition and structure of their cell wall, which is revealed by a Gram stain. Gram-positive bacteria possess a thick peptidoglycan layer. Gram-negative bacteria, on the other hand, possess a thin peptidoglycan layer between the outer and cytoplasmic membranes (Fig. 3). EOs have been shown to have antibacterial activity against both Gram-negative (e.g., Escherichia. coli and Pseudomonas aeruginosa) and Gram-positive bacteria (e.g., S. aureus). However, Gram-negative bacteria appear to be less susceptible to EOs, likely due to the presence of an outer membrane which may limit the diffusion of hydrophobic compounds into the cell. ${ }^{19}$ Of the bacterial strains tested, the strain least sensitive to EOs is $P$. aeruginosa. ${ }^{14}$

The activity of EOs is independent from the antibiotic resistance phenotype. Consequently, EOs are also active on MRBs. The growth of certain MRBs such as methicillinresistant $S$. aureus (MRSA) ${ }^{20}$ and vancomycin-resistant enterococci ${ }^{21}$ can be inhibited by certain EOs, including citrus, lavender, mint, juniper, tea tree, thyme and eucalyptus oils. Another study showed that EOs extracted from two species of Korea thyme were able to inhibit the growth of pathogenic bacteria such as Streptococcus pneumoniae, Salmonella typhimurium, Salmonella entereditisand S. aureus. $^{22}$

\section{Antibacterial Actions of Phenolic Compounds}

Phenols are aromatic chemical compounds with an attached hydroxyl group. Phenols include thymol 


\section{$\underline{1 . T e r p e n e s}$}

Precursor<smiles>C=C(C)CCOP(=O)([O-])OP(=O)(O)O</smiles>

Isopenténylpyrophosphate

- Monoterpenes

Carbure monocyclic<smiles>CCCCCCCC(C)C</smiles>

Alcoholacyclic

Geraniol
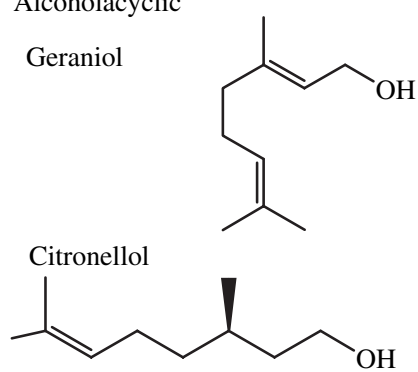

Sabinene

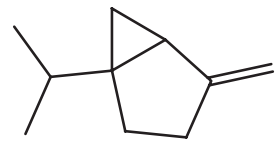

Carbure bicyclic

Alpha-pinene<smiles>CC1=CC[C@H]2C[C@H]1C2(C)C</smiles>

Phenol<smiles>CC(C)c1ccc(C(=O)Cl)c(O)c1</smiles>

Beta-pinene<smiles>C=C1CC[C@H]2C[C@H]1C2(C)C</smiles>

Figure 1. Terpene chemical structures.

(5-methyl-2-propan-2-ylphenol), carvacrol (2-methyl5-propan-2-ylphenol) and eugenol (4-allyl-2-methoxyphenol). The strong antimicrobial activity of phenols is due to the presence of a hydroxyl group, which can donate electrons to functional groups on cell membranes (Fig. 4). Thus, EOs saturated with phenols (e.g., thyme, clove and oregano oils) possess the highest antibacterial activity. The mechanism of action of these antimicrobial components is microorganism-dependent ${ }^{13,14,23}$ (Fig. 5).

The specific mechanism of action of these EO components remains poorly characterized, however. The antibacterial properties of EO components are attributed to several properties, including the components' lipophilicity, which enables EO accumulation in the cytoplasmic membrane. This accumulation leads to alteration of the fatty acid profile and modification of the cell envelope's structure. ${ }^{24}$ This alteration of fatty acid profiles, in addition to the alteration of phospholipids in the bacterial membranes, increases membrane permeability. Phenolic components are able to penetrate mitochondrial membranes, leading to potassium ion leakage. The leakage of ions and cellular components caused by pores in the bacterial membrane leads to a cessation of energy metabolism and bacterial death. ${ }^{24-26}$ Some studies carried out by scanning electron microscopy (SEM) showed membrane pore formation and loss of intracellular material in E. coli $\mathrm{O} 157: \mathrm{H} 7$ cells following treatment with oregano EO. ${ }^{27}$

The chemical structure of EO components directly affects their activity. A study by Ultee ${ }^{17}$ revealed the importance of the benzene ring: menthol, which lacks a benzene ring, was significantly less active than carvacrol, which possesses a benzene ring. While a hydroxyl group in the benzene ring is essential for activity, the hydroxyl group's position has little influence on the degree of activity. ${ }^{17,28}$ Thus, thymol and carvacrol, which differ in the position of the hydroxyl group (ortho and meta, respectively) exhibit comparable activities on Bacillus cereus, S. aureus and $P$. aeruginosa strains. ${ }^{17,28}$

The aromatic ring of phenols, which is highly electronegative, attracts oxygen electrons away from the hydroxyl group. This attraction facilitates interactions between the hydroxyl group and monovalent cations 
2. Aromatic compounds

Precursors<smiles>NC(Cc1ccccc1)C(=O)O</smiles>

Phenylalanine<smiles>NC(Cc1ccc(O)cc1)C(=O)O</smiles>

Tyrosine
Aldehyde

Cinnamaldehyde

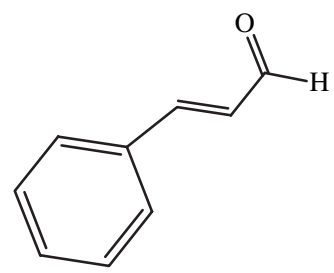

Methoxy derivative

Estragole

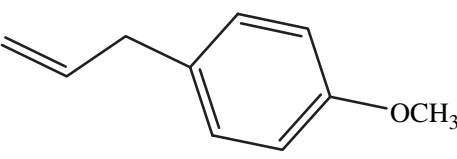

Alcohol

Cinnamyl alcohol

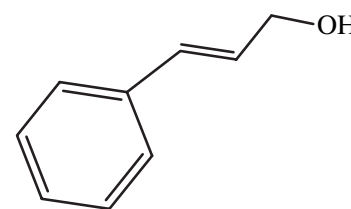

Phenol

Eugenol<smiles>C=CCc1ccc(O)c(OC)c1</smiles>

Methylene dioxy compound

Safrole<smiles>C=CCc1ccc2c(c1)OCO2</smiles>

Figure 2. Chemical structures of aromatic compounds.

$(\mathrm{H}+/ \mathrm{K}+)$ through the cell membrane, altering both $\mathrm{pH}$ and potassium gradients across the membrane. ${ }^{29}$ Furthermore, the aromatic ring's electronegativity depolarizes the membrane, altering electron flow and increasing membrane permeability, leading to the membrane destabilization. ${ }^{14}$

To insulate itself from environmental effects, a cell regulates its fluidity by changing the average fatty acid chain length, ratio of protein and fatty acid composition in its membrane. ${ }^{24}$ For example, a decrease in growth temperature induces an increase in unsaturated fatty acids and a concurrent increase in membrane fluidity in several microbes. ${ }^{30}$ In the same study, it was shown that the unsaturated fatty acid contents of E. coli and Salmonella were altered by the presence of carvacrol and eugenol. Pseudomonas fluorescens and S. aureus were unaffected, however, likely due to their naturally high resistance to antimicrobial compounds.
In one study, it was shown that $E$. coli $\mathrm{K} 12$ increases the degree of saturation of its fatty acids in the presence of sub-lethal concentrations of phenol and phenol derivatives. ${ }^{31}$ Moreover, the addition of saturated fatty acids or lecithin to the culture media reduces the inhibitory effects of phenols. These data suggest that absorption of free fatty acids into the $E$. coli membrane provides some protection against phenols.

Various methods are used to characterize membrane lipid molecules. One such method is differential scanning calorimetry (DSC), which was used by Cristani ${ }^{32}$ to evaluate the ability of monoterpenes to interact with pure dimyristoylphosphatidylcholine (DMPC) liposomes. The results showed that carvacrol induces a decrease in the liposome's transition melting temperature. An enthalpy variation was also observed upon comparison with reference samples, suggesting that monoterpenes act as substitutional 


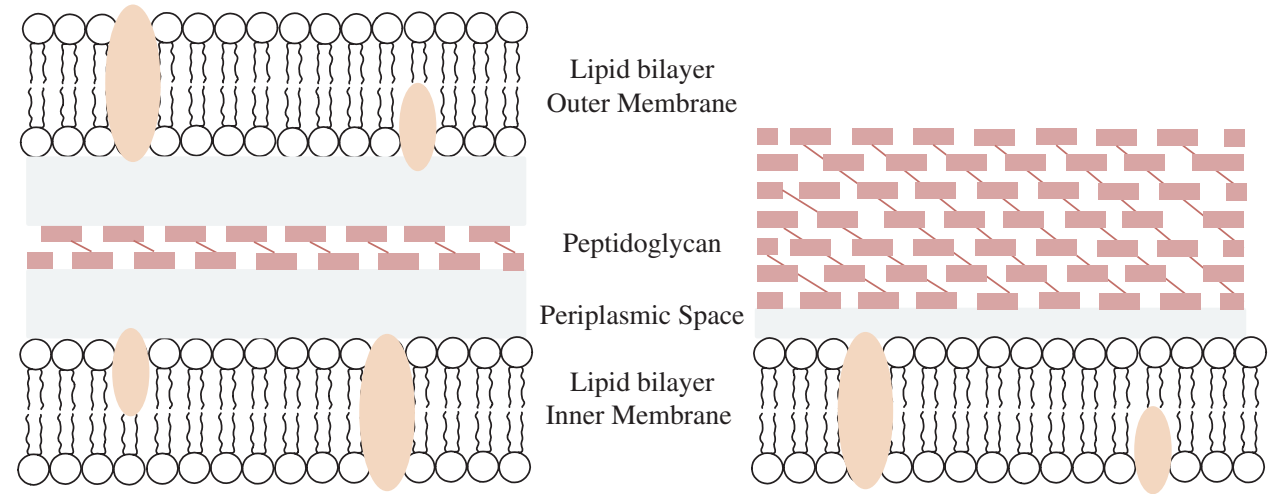

Figure 3. Composition of gram-positive and gram-negative bacteria.

impurities. ${ }^{32}$ Ultee $^{18}$ calculated the phase transition temperature from FTIR (Fourier-transformed infrared) spectra, noting a decrease in the melting temperature of $B$. cereus membranes after carvacrol addition. Another study by Di Pasqua ${ }^{24}$ using total lipid extraction and analytical gas chromatography demonstrated alterations in cellular fatty acid composition in the presence of thymol, carvacrol and eugenol on E. coli and Salmonella strains.

Oxygenated compounds that can cross the membrane can also influence the expression of certain genes and can bind to cytoplasmic proteins. A study conducted by Dubois-Brissonnet ${ }^{33}$ showed decreased expression of cyclopropane synthetase, which is involved in fatty acid synthesis, in the presence of phenolic compounds.

The action of phytophenolic compounds also depends on the stage of cell growth: one study demonstrated that dividing cells of Saccharomyces cerevisiae are more sensitive than quiescent cells to these compounds. One can hypothesize that phytophenolic compounds are able to penetrate the cell membrane more effectively during the first budding stages. ${ }^{13}$

\section{Carvacrol and Thymol}

Carvacrol and thymol are phenolic terpenes. These two compounds are the major components of oregano (80\%) and thyme (10\% to $64 \%)$ oils.

As mentioned previously, carvacrol and thymol have very similar chemical structures, differing only in the position of the hydroxyl group on the phenolic ring. Therefore, one could expect the compounds to have similar activities on bacteria. Nevertheless, it is important to note that antibacterial activity depends on factors

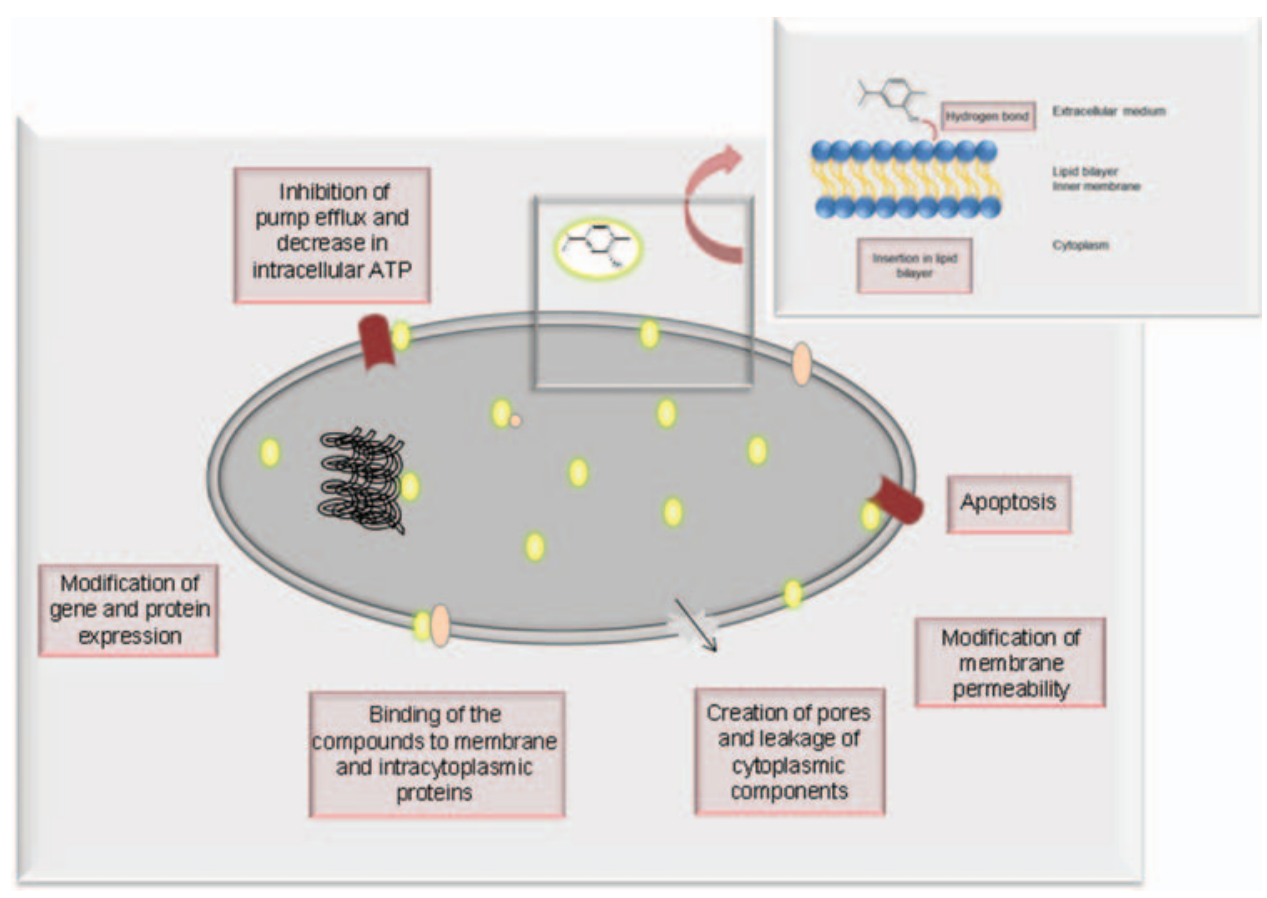

Figure 4. Mode of antibacterial action of phenolic compounds. 


\begin{tabular}{|c|c|c|c|c|}
\hline & Chemical structure & Bacteria & Antibacterial actions & References \\
\hline \multirow[t]{6}{*}{ Thymol } & \multirow[t]{6}{*}{ Phenol (terpene) } & $\begin{array}{l}\text { Pseudomonas aeruginosa } \\
\text { Staphylococcus aureus }\end{array}$ & Damage to membrane integrity & [40] \\
\hline & & $\begin{array}{l}\text { Staphylococcus aureus } \\
\text { Escherichia coli }\end{array}$ & $\begin{array}{l}\text { Permeability modification, } \\
\text { Loss of intracellular components }\end{array}$ & {$[42]$} \\
\hline & & Listeria monocytogenes & $\begin{array}{l}\text { Decrease in bacteria size } \\
\text { Bacterial wall modification } \\
\text { Cytoplasm aggregation }\end{array}$ & [43] \\
\hline & & Pseudomonas fluorescens & Modification of fatty acids in membranes & [24] \\
\hline & & Escherichia coli & Modification of cytoplasmic membrane & [26] \\
\hline & & $\begin{array}{l}\text { Escherichia coli } \\
\text { Salmonella typhimurium }\end{array}$ & $\begin{array}{l}\text { Disintegrate outer membrane } \\
\text { Decrease intracellular ATP }\end{array}$ & [41] \\
\hline \multirow[t]{5}{*}{ Carvacrol } & \multirow[t]{5}{*}{ Phenol (terpene) } & $\begin{array}{l}\text { Pseudomonas aeruginosa } \\
\text { Staphylococcus aureus }\end{array}$ & Damage to membrane integrity & {$[40]$} \\
\hline & & Bacillus cereus & $\begin{array}{l}\text { Insertion in lipid bilayer } \\
\text { Increase in membrane permeability } \\
\text { Decrease in intracellular ATP } \\
\text { Decrease in membrane potential Ion leakage }\end{array}$ & {$[17]$} \\
\hline & & $\begin{array}{l}\text { Brochothrix thermosphacta } \\
\text { Salmonella typhimurium }\end{array}$ & Modification of fatty acids in membranes & [24] \\
\hline & & $\begin{array}{l}\text { Escherichia coli } \\
\text { Escherichia coli } \\
\text { Salmonella typhimurium }\end{array}$ & $\begin{array}{l}\text { Modification of cytoplasmic membrane } \\
\text { Disintegration of outer membrane }\end{array}$ & $\begin{array}{l}{[26]} \\
{[41]}\end{array}$ \\
\hline & & Escherichia coli & $\begin{array}{l}\text { Alteration of proteins (heat shock protein } 60 \text { ); } \\
\text { inhibition of flagellin synthesis }\end{array}$ & [39] \\
\hline \multirow[t]{4}{*}{ Eugenol } & \multirow[t]{4}{*}{$\begin{array}{l}\text { Phenol (aromatic } \\
\text { compound) }\end{array}$} & $\begin{array}{l}\text { Listeria monocytogenes } \\
\text { Lactobacillus sakei }\end{array}$ & $\begin{array}{l}\text { Cell wall alteration } \\
\text { Inhibition of ATP synthases in membranes }\end{array}$ & {$[45]$} \\
\hline & & Bacillus cereus & Inhibition of amylase and protease production & [44] \\
\hline & & $\begin{array}{l}\text { Brochothrix thermosphacta } \\
\text { Salmonella typhimurium }\end{array}$ & Modification of fatty acids in membranes & [24] \\
\hline & & Enterobacter aerogenes & Binding to protein (histidine decarboxylase) & [47] \\
\hline
\end{tabular}

Figure 5. Antibacterial action of phenols.

such as type of microorganism, $\mathrm{pH}$ and incubation temperature. $^{34}$

The mechanism of carvacrol activity has been studied in B. cereus. ${ }^{17,18}$ According to Ultee, ${ }^{18}$ carvacrol acts as a protonophore, a carrier proton that binds to the lipid bilayer. Carvacrol inserts into the membrane and interacts with cations via its hydroxyl group, disrupting the membrane's structure. ${ }^{17}$ This interaction decreases the intracellular ATP concentration and the membrane potential in addition to causing leakage of ions, ATP, amino acids and nucleic acids, leading to cell death.

Studies by Cristani ${ }^{32}$ with E. coli ATCC showed that carvacrol inserts into cell membranes, affecting membrane lipid composition by destabilizing the cell membrane and increasing membrane fluidity. The presence of carvacrol ultimately leads to increased membrane proton permeability and a type of cytoplasmic clotting. ${ }^{17}$ In addition, carvacrol can pass through the lipid bilayer and interact with cytoplasmic targets. ${ }^{32}$ By inserting into the membrane and binding to cytoplasmic protein complexes, eugenol and carvacrol affect both membrane integrity and functionality. ${ }^{35}$

Unfortunately, bacterial growth has been observed in the presence of moderate concentrations of phytophenolic actives. This growth has been explained by an adaptive mechanism: cells can adapt to the presence of antimicrobial agents by altering their membrane's fatty acid profile. Cells with a persistent phenotype are more likely to survive and proliferate. ${ }^{36}$ Even though no specific resistances or adaptations to EOs have been identified, a resistance to carvacrol by $B$. cereus was observed after growing in the presence of sub-lethal carvacrol concentrations. ${ }^{18}$

Studies have demonstrated that carvacrol's hydrophobicity leads to the removal of polysaccharides from the membrane and an increase membrane permeability. ${ }^{30,37}$ Microorganisms develop adaptive mechanisms against the harmful effects of cytotoxic components at low concentrations $^{38}$ such as the restoration of membrane fluidity, preservation of membrane integrity and the ability to expel foreign elements. An increase in carvacrol concen- 
trations is associated with an accumulation of carvacrol in the membrane, leading to more severe damage. ${ }^{17}$

Another study reported that carvacrol alters the expression of several proteins in E. coli O157:H7:carvacrol increases the amount of heat shock protein 60 and strongly inhibits the synthesis of flagellin. ${ }^{39}$

Thymol's mechanisms of action are very close to those of carvacrol. ${ }^{40}$ Thymol is known to bind to the hydrophobic parts of membrane proteins in $P$. aeruginosa and $S$. aureus through hydrogen bonding. Thymol binding causes changes in the bacteria's permeability characteristics. ${ }^{40}$ Another study showed that carvacrol and thymol cause a decrease in intracellular ATP concentration, leading to disruption of the cell membrane in E. coli and $S$. typhimurium. ${ }^{41}$ The action of thymol has also been studied in artificial membranes. ${ }^{42}$ Thymol's effectiveness was found to depend on the membrane's composition and charge. Upon entering the cytoplasmic membrane, thymol alters the membrane's permeability, resulting in the loss of intracellular material. A transmission electron microscopy (TEM) study reported that the use of thymol on L. monocytogenes cells resulted in decreased cell size, an altered bacterial cell wall and lack of cytoplasm. ${ }^{43}$

\section{Eugenol}

Another phenolic compound is eugenol, the major component of clove oil (approximately 75 to $85 \%$ ).

Currently, few studies have examined the mechanisms of eugenol action. It has been reported that this antimicrobial agent inhibits the production of enzymes such as amylases and proteases ${ }^{44}$ in $B$. cereus. Eugenol also causes cell wall degradation, resulting in inhibition of membranebound ATP synthases. ${ }^{45}$

A study reported that eugenol exhibits a lower antibacterial activity than carvacrol. This difference can be attributed to eugenol's lower hydrophobicity, which is due to its ortho methoxyl group. ${ }^{46}$

It has been demonstrated that the hydroxyl groups in eugenol can bind and inhibit proteins such as histidine decarboxylase in Enterobacter aerogenes. ${ }^{47}$ A study reported that eugenol has bactericidal effects on L. monocytogenes, acting as an ion transporter and preventing the accumulation of intracellular ATP ${ }^{48}$ Another study showed that E. coli and S. aureus bacteria treated with eugenol exhibit altered membrane permeabilities due to potassium ion leakage. ${ }^{49}$ Inhibition of histidine decarboxylase in E. aerogenes has been recorded in the presence of high eugenol concentrations. The authors suggest that eugenol inhibits histidine decarboxylase synthesis, directly affecting the cell's metabolic energy. ${ }^{47}$

\section{Combination of Phenol Actives}

To maximize the antibacterial potential of phenolic compounds, one must maximize the number of bacterial species affected by these compounds. We have seen than these antibacterial agents have many mechanisms of action, including insertion between fatty acids in the bacterial membrane, attachment to proteins and membrane enzymes, inhibition of DNA/RNA synthesis, inhibition of proteins and polysaccharides and chelation of trace elements (e.g., iron).$^{50}$ Considering that a microorganism could be resistant to a particular antimicrobial agent, it would be interesting to assess the activities of mixtures of different antimicrobial agents. It has been shown that when microorganisms are exposed to a combination of antimicrobial agents, the risk of resistance development is significantly limited. ${ }^{26}$

Interactions between various EO components may also affect antibacterial activity, as combining components can result in synergistic, additive or antagonist effects. ${ }^{18,51,52}$ For example, the effectiveness of thyme EOs against $S$. aureus and P. aeruginosa is due to the synergy between its major components, carvacrol and thymol. ${ }^{40}$

A number of studies have tested the inhibitory effects of natural antibacterial mixtures (carvacrol, thymol, eugenol) or synthetic antimicrobial agents against several bacteria. ${ }^{25,53-55}$

For example, a study by Garcia-Garcia ${ }^{56}$ showed that among binary and ternary mixtures of carvacrol, thymol and eugenol tested against L. innосиа, the ternary mixture exhibited the highest antimicrobial activity, ${ }^{56}$ while the least effective mixture was carvacrol-eugenol. In addition, this study demonstrated that carvacrol is the most effective antimicrobial agent against $L$. іпnосиа compared to thymol and eugenol. Another study demonstrated that binary combinations of carvacrol, thymol or eugenol with potassium sorbate effectively inhibited growth of L. innocua, $S$. typhimurium and E. coli. ${ }^{55}$ The natural antimicrobials were more effective than potassium sorbate.

Studies describing the activities of polyphenols against a variety of microorganisms showed that eugenol has a significantly lower antimicrobial activity compared to other EO components. ${ }^{57} \mathrm{~A}$ study evaluating combinations of thymol/eugenol, thymol/carvacrol and carvacrol/eugenol demonstrated a synergistic effect against $E$. coli. The best synergistic effect was observed for a combination of eugenol with thymol or carvacrol, which decreased the MIC against E. coli from $1600 \mathrm{mg} / \mathrm{L}$ to $400 \mathrm{mg} / \mathrm{L} .^{54}$

Another study showed that an appropriate ratio of carvacrol/thymol maximizes the synergistic antibacterial effects of the compounds against lactobacilli. ${ }^{58}$

However, it is difficult to anticipate the effects of combinations of antimicrobial agents against bacterial strains. Despite the fact that there is very little scientific knowledge regarding the agents' mechanisms of interaction, many synergistic combinations have been observed.

\section{ENCAPSULATION OF PHENOLIC COMPOUNDS EXTRACTED FROM EOs}

EOs and their major components are very poorly soluble in water, and injection of unmodified EOs into the 


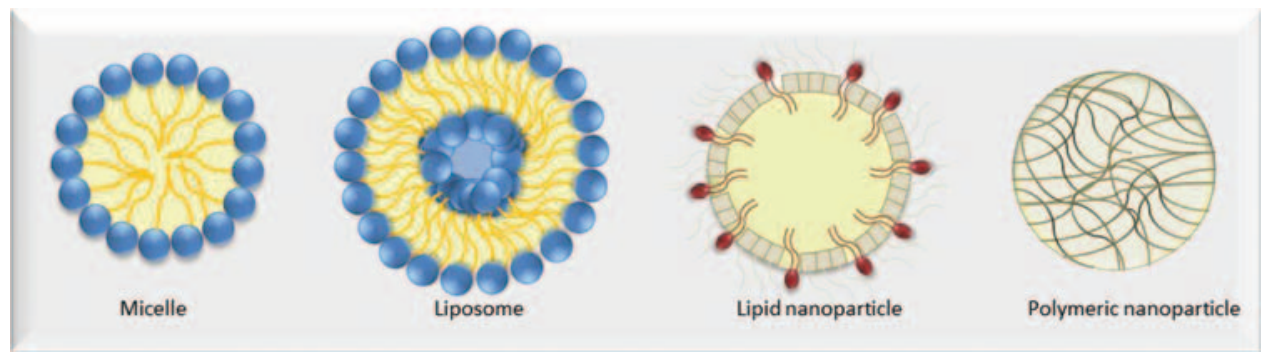

Figure 6. Representation of different types of nanoparticles.

bloodstream is impossible. In most cases, EOs must to be administered orally. Unfortunately, EO components tend to bind to hydrophobic components in food, decreasing the components' bioavailability and antimicrobial activity. ${ }^{59}$ Additionally, facilitated degradation and consequent loss of chemical reactivity is an additional drawback to EOs. ${ }^{59}$

The EO characteristics described above necessitate a delivery system with appropriate hydrophilic characteristics. Thus, encapsulation of EOs, especially phenols, could be a viable alternative to increase antimicrobial effectiveness.

Nanoparticles have many advantages over other delivery systems, including incorporation of both hydrophilic and lipophilic agents, protection of encapsulated drugs from degradation and a potential for sustained release. Nanoparticles also allow for high drug carrier capacity, improve drug bioavailability, eliminate drug toxicity and target the specific site of action. Moreover, encapsulation allows for controlled release of EOs and their major components. ${ }^{60}$ Currently cyclodextrins (cyclic carbohydrates derived from starch) are used for EO encapsulation. ${ }^{60-62}$

Different types of encapsulation with phytophenols have already been tested, including emulsions, liposomes, micelles and solid or lipid particles made of proteins, carbohydrates or crystallized lipids (Fig. 6). Among these nanocarriers, nanoparticles are the most commonly used method to demonstrate antibacterial activity (Fig. 7).

Nanoparticles range from 10 to $1000 \mathrm{~nm}$ in diameter and can encapsulate various therapeutic agents such as drugs, radionucleotides or DNA. Ideally, an optimal delivery system would target the antibacterial agent directly to the site of infection. Encapsulation of phenols in a nanoparticle system is a viable and effective approach to increase the stability of lipophilic bioactive components. Additionally, some studies have reported no loss of antibacterial efficacy after encapsulation $^{63-65}$ (Fig. 8).

In addition, due to their subcellular size, nanoparticle systems should increase the biological activity of phenols and therefore their antimicrobial activity by activating passive cellular uptake mechanisms. ${ }^{66}$ Furthermore, encapsulation of phenols protects the phenols against the environment (e.g., oxygen, light, moisture, $\mathrm{pH}){ }^{67}$

\section{Emulsions and Nanoemulsions}

Emulsion systems are the most frequently used encapsulation system. These systems ensure a uniform distribution of partially or completely hydrophobic components in a hydrophilic medium. ${ }^{36}$ Emulsions are thermodynamically unstable and tend to break down over time; therefore, emulsions must to be carefully formulated to remain stable for as long as possible. The functionality of emulsions is influenced by the concentration and size distribution of the droplets. Thus, the choice of a suitable emulsifier is critical to achieving a stable emulsion. Traditionally, emulsions have droplet sizes above $100 \mathrm{~nm}$.

Several studies have demonstrated the suitability of EO encapsulation in emulsions stabilized by proteins, polymers and polysaccharides. ${ }^{68-70}$

The use of an oily solid emulsion reduces the volatility of antimicrobial agents trapped in the oil-crystallized structure, and this system is capable of protecting agents against environmental factors. For example, the encapsulation of juniper oil by solid lipid micro-particles reduces the volatility of the antimicrobial agent. ${ }^{71}$

Recently, a new class of emulsions with finer particles has gained interest. These systems, called nanoemulsions, consist mainly of droplet dispersion with diameters between 10 and $100 \mathrm{~nm}$. Production of nanoemulsions has become possible by using techniques for high-pressure homogenization, such as ultrasonication or microfluidization as well as the phase inversion temperature (PIT) method. $^{72,73}$ The main phenomenon that can affect the stability of nanoemulsions is Ostwald ripening. This phenomenon causes migration of the smaller droplets to the larger droplets through the continuous phase. Migration occurs when the oil phase has an appreciable solubility in the aqueous phase. This phenomenon results in an increase in average droplet size ${ }^{61}$ However, previous studies have shown that this phenomenon can be inhibited by incorporating into the droplets sufficient levels of oils that are highly insoluble in the aqueous phase. ${ }^{74}$

Encapsulation of phenols from EOs inside oil-inwater $(\mathrm{o} / \mathrm{w})$ emulsions or nano-emulsions has been performed. ${ }^{36,61,75}$ Chang $^{61}$ used thyme oil nano-emulsions against the yeast Zygosaccharomyces bailii, showing that the oil phase had an appreciable antimicrobial activity. 


\begin{tabular}{|c|c|c|c|c|c|c|}
\hline $\begin{array}{l}\text { Nano-system } \\
\text { delivery }\end{array}$ & Advantages & Phenols & Composition & Size (nm) & Bacterial strain & References \\
\hline \multirow[t]{9}{*}{ Micro-emulsion } & Nanometer size & Eugenol & Tween-20 (polyoxyethylene) & $8 \mathrm{~nm}$ & Staphylococcus aureus & [90] \\
\hline & $\begin{array}{l}\text { Promotion of active } \\
\text { stability }\end{array}$ & & Micellar solution & & Escherichia coli & \\
\hline & Reduction of toxicity & & & & Pseudomonas aeruginosa & \\
\hline & Biodegradability & & & & Salmonella typhimurium & \\
\hline & $\begin{array}{l}\text { Promotion of active } \\
\text { bioavailability }\end{array}$ & & & & Listeria monocytogenes & \\
\hline & $\begin{array}{l}\text { Protection of active } \\
\text { degradation }\end{array}$ & & & & Bacillus cereus & \\
\hline & Targeting specific cells & & & & & \\
\hline & & Carvacrol & $\begin{array}{l}\text { Tricylglyceride } \\
\text { (Miglyol 812N) }\end{array}$ & $80 \mathrm{~nm}-3000 \mathrm{~nm}$ & Escherichia coli & [36] \\
\hline & & Eugenol & Tween 80 & & Listeria іппосиа & \\
\hline \multirow[t]{5}{*}{ Nano-emulsion } & & Carvacrol & Tween 20 & $123 \mathrm{~nm}-293 \mathrm{~nm}$ & Saccharomyces cerevisiae & [67] \\
\hline & & & Glycerol monooleate & & Escherichia coli & \\
\hline & & & Lecithin & & Lactobacillus delbrueckii & \\
\hline & & & Pea proteins & & & \\
\hline & & & Sugar ester & & & \\
\hline \multirow[t]{9}{*}{ Liposome } & & Carvacrol & Phosphatidylcholine & I & Staphylococcus aureus & [79] \\
\hline & & Carvacrol/ & Cholesterol & & Staphylococcus epidermidis & \\
\hline & & Thymol (6:1) & & & Staphylococcus mutans & \\
\hline & & & & & Staphylococcus viridans & \\
\hline & & & & & Pseudomonas aeruginosa & \\
\hline & & & & & Escherichia coli & \\
\hline & & & & & Enterobacter cloacae & \\
\hline & & & & & Klebsiella pneuтопiae & \\
\hline & & & & & Listeria monocytogenes & \\
\hline \multirow[t]{2}{*}{ Micelle } & & Carvacrol & Surfynol 465 and $485 \mathrm{~W}$ & $3 \mathrm{~nm}-17 \mathrm{~nm}$ & Escherichia coli & [87] \\
\hline & & Eugenol & & & Listeria monocytogenes & \\
\hline \multirow[t]{14}{*}{ Nanoparticle } & & Thymol & Zein & $200 \mathrm{~nm}$ & Escherichia coli & [92] \\
\hline & & & Sodium Caseinate & & Salmonella & \\
\hline & & $\begin{array}{l}\text { Thymol } \\
\text { Carvacrol }\end{array}$ & Zein & $50 \mathrm{~nm}-328 \mathrm{~nm}$ & Escherichia coli & [93] \\
\hline & & Thymol & $\begin{array}{l}\text { Ethylcellulose/ } \\
\text { methylcellulose }\end{array}$ & $865 \mathrm{~nm}$ & $\begin{array}{l}\text { Escherichia coli } \\
\text { Pseudomonas aeruginos } \\
\text { Staphylococcus aureus }\end{array}$ & {$[95]$} \\
\hline & & Carvacrol & $\begin{array}{l}\text { Chitosan } \\
\text { Tween } 60 \\
\text { Sodium Tripolyphosphate }\end{array}$ & $40-80 \mathrm{~nm}$ & $\begin{array}{l}\text { Escherichia coli } \\
\text { Bacillus aureus }\end{array}$ & {$[65]$} \\
\hline & & Carvacrol & $\begin{array}{l}\text { Sodium Iriporyphospnate } \\
\text { Chitosan }\end{array}$ & $220 \mathrm{~nm}-260 \mathrm{~nm}$ & $\begin{array}{l}\text { Staphylococcus aureus } \\
\text { Staphylococcus aureus }\end{array}$ & [63] \\
\hline & & Eugenol & Sodium Tripolyphosphate & & Escherichia coli & \\
\hline & & Thymol & Chitosan & $20 \mathrm{~nm}-190 \mathrm{~nm}$ & $\begin{array}{l}\text { Staphylococcus aureus } \\
\text { Escherichia coli } \\
\text { Bacillus subtilis }\end{array}$ & [111] \\
\hline & & Eugenol & Protein isolate (WPI) & $130 \mathrm{~nm}-315 \mathrm{~nm}$ & Listeria monocytogenes & {$[102]$} \\
\hline & & Carvacrol & $\begin{array}{l}\text { Maltodextrin (MD) } \\
\text { poly(DL-lactide-co-glycolide) } \\
\text { Phosphatidylcholine }\end{array}$ & $210 \mathrm{~nm}$ & $\begin{array}{l}\text { Escherichia coli } \\
\text { Staphylococcus epidermis }\end{array}$ & [101] \\
\hline & & Eugenol & poly(DL-lactide-co-glycolide) & $170 \mathrm{~nm}-185 \mathrm{~nm}$ & Salmonella entereditis & [100] \\
\hline & & & poly(vinyl alcohol) & & Salmonella typhimurium & \\
\hline & & & & & Listeria monocytogenes & \\
\hline & & & & & Listeria іппосиа & \\
\hline
\end{tabular}

Figure 7. Encapsulation of phenols by different nanodelivery systems.

Another study conducted by $\mathrm{Ziani}^{75}$ reported the use of thyme oil-in-water nano-emulsions stabilized by nonionic, cationic, anionic surfactants ((Tween 80, lauric alginate (LAE), sodium dodecyl sulfate (SDS)) against four strains of acid-resistant spoilage yeasts. However, the results showed that the combinations of antimicrobial oil (thyme oil) and antimicrobial ionic surfactant (SDS, LAE) had an antagonistic impact on antimicrobial efficacy. 
(a)

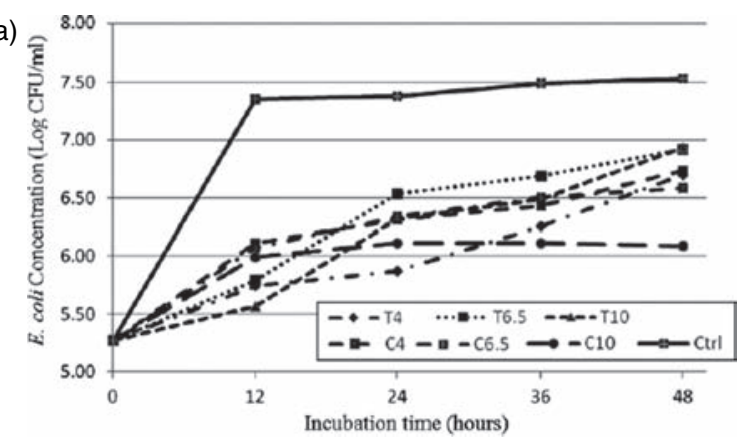

(b)

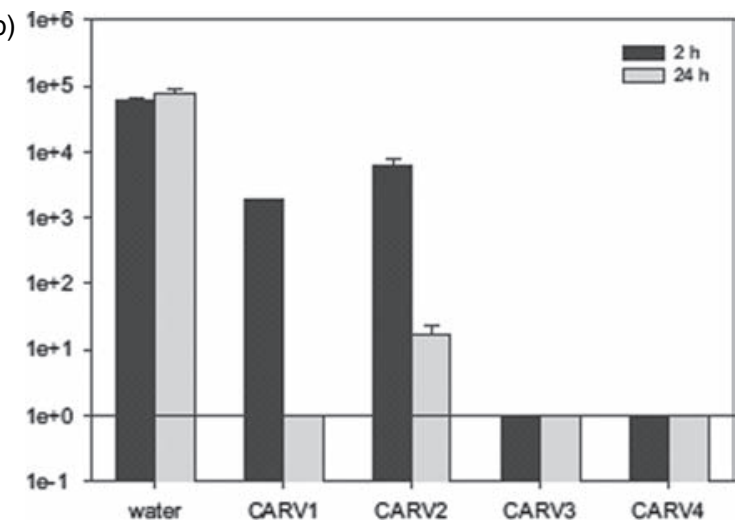

Figure 8. Growth curves of $E$. coli exposed to nanosystem deliveries.

Terjun and al. ${ }^{36}$ focused on nano-emulsions made from Miglyol $812 \mathrm{~N}$ (triacylglyceride) and Tween 80 containing various concentrations of eugenol and carvacrol. The results showed that emulsions with large droplet sizes $(3000 \mathrm{~nm})$ were more effective at inhibiting the growth of L. innocua than emulsions with smaller droplets $(80 \mathrm{~nm})$, as eugenol and carvacrol concentrations decreased with droplet size. In addition, the results showed that, in contrast to the carvacrol-loaded emulsion, the eugenol-loaded emulsion did not inhibit L. innocua growth at the concentrations tested.

A another study reported systems composed of biocompatible components such as chitosan ${ }^{76}$ and calcium alginate. ${ }^{77}$ These systems were used to control EO release in the mouth (chitosan) or small intestine (calcium alginate).

\section{Liposomes}

Liposomes are nanocarriers whose structure is similar cell membranes. ${ }^{78}$ Liposomes are spherical particle consisting of amphiphilic molecules (e.g., phospholipids, cholesterols, sphingomyelins) arranged in one or several lipid bilayers enclosing an aqueous compartment.

Studies have shown that liposomes enhance the antimicrobial activity of Origanum dictamnus, ${ }^{79}$ extracts of lemon, ${ }^{80}$ extracts from myrtus ${ }^{80}$ and Artemisia arborescens EOs. ${ }^{81}$

It has been shown that for certain concentrations, thymol and carvacrol inhibit the peroxidation of phospholipid liposomes, suggesting that these agents are strong antioxidants. ${ }^{82}$ Similarly, the inhibition of EO oxidation in Origanum plants is highly dependent on the concentration of carvacrol and thymol. ${ }^{83}$

Liolios $^{79}$ showed that carvacrol and thymol incorporated into liposomes (made from phosphatidyl choline) possessed higher antibacterial power than the nonencapsulated actives against L. monocytogenes.

\section{Micelles and Microemulsions}

Micelles are spontaneously formed when amphiphilic molecules (with adapted Hydrophilic Lipophilic Balance values) are inserted in water. Micelles are composed of an inner core of interacting hydrophobic segments surrounded by an outer hydrophilic corona, which serves as a stabilizing interface with the external aqueous environment. ${ }^{84}$ Micelles are generally between 5 and $100 \mathrm{~nm}$ in diameter, depending on the nature of the amphiphilic molecules (e.g., small molecules, polymers or other macro molecules).

Studies have shown that micellar based systems increase the antimicrobial activity of eugenol and carvacrol. ${ }^{35,85-87}$ One of the studies demonstrated growth inhibition of four strains of E. coli and L. monocytogenes by using carvacrol and eugenol solubilized in non-ionic micelles with Surfynol 465 and $485 \mathrm{~W}$ surfactants. ${ }^{85}$ The results showed that the antimicrobial activity of Surfynol $485 \mathrm{~W}$ micelle is higher with eugenol compared to carvacrol.

Studies realized by Perez-Conesa ${ }^{88,89}$ showed that a micellar nonionic surfactant Surfynol 485 W solution containing eugenol and carvacrol was effective against biofilms containing $L$. monocytogenes and E. coli. $L$. monocytogenes strains were more resistant to these antimicrobial systems than E. coli strains.

In another study, inhibition of L. monocytogenes and E. coli $\mathrm{O} 157: \mathrm{H} 7$ was tested with eugenol encapsulated in micellar solutions at different $\mathrm{pHs}(\mathrm{pH} \mathrm{5,6}$ and 7) and different temperatures $\left(10^{\circ} \mathrm{C}, 22^{\circ} \mathrm{C}\right.$ and $\left.32{ }^{\circ} \mathrm{C}\right)$. Antibacterial effectiveness decreased when $\mathrm{pH}$ increased but was not affected by temperature. ${ }^{86}$

Microemulsions correspond to ternary systems in a thermodynamic equilibrium state composed of water or oil-loaded micelles. These systems maintain their structure as long as system temperature and composition are unchanged. A study by Hamed ${ }^{90}$ demonstrated that eugenol microemulsions (prepared using Tween 20) possessed higher antioxidant activity than clove EO microemulsions. Moreover, eugenol microemulsions seemed more effective against $S$. aureus, E. coli, P. aeruginosa, S. typhi and $B$. cereus than clove EO microemulsions.

Microemulsion systems enhance the activity of phytophenols ${ }^{86}$ and these systems are known to possess a complex micellar topology. However, these systems may have some disadvantages, including a lack of physical stability after dilution, undesirable interactions with food and the degradation or loss of particular components. 


\section{Nanospheres-Nanocapsules}

There are two main types of nanoparticle that can be used to encapsulate lipophilic compounds. The first type corresponds to lipidic or polymeric systems, where the entire nanoparticle structure is cohesive (matrix systems). The solid lipid nanosphere (SLN) is an important member of this group. The second type corresponds to nanocapsules composed of an oily core (or aqueous core in some cases) surrounded by a cohesive polymeric or lipidic shell (nano-capsules). Lipid nano-capsules (LNCs) are the most used system in this category. LNC shells can consist of polymer and/or lipids in different proportions, with sizes in the 10 to $200-500 \mathrm{~nm}$ range.

Polymeric nanoparticles are usually prepared from hydrophobic synthetic polymers or copolymers such as polylactide/polyglycolide (PLA/PLGA) or natural polymers such as albumin, gelatin, collagen, and chitosan. A variety of therapeutic agents including lipophilic or hydrophilic drugs can be encapsulated in such systems.

Several studies have reported the use of nanospheres to encapsulate antimicrobial agents. Parris ${ }^{91}$ used corn zein to produce nanospheres encapsulating oregano and thyme EOs. The aim of Parris's study was to target the release of each active to a specific site in order to optimize each compound's antibacterial properties. Another study explored the suitability of thymol-loaded zeinsodium caseinate (SC) nanoparticle-based films, ${ }^{92}$ finding antimicrobial activity against E. coli and Salmonella for a thymol-to-zein ratio of $30-40 \%$. $\mathrm{Wu}^{93}$ demonstrated the antioxidant and antimicrobial properties of carvacrol and thymol zein nanoparticles against $E$. coli.

Kavoosi $^{94}$ reported the antimicrobial and antioxidant properties of gelatin films incorporating thymol. The results showed the effectiveness of this system against S. aureus, B. cereus, E. coli and P. aeruginosa. Another study conducted by Wattanasatcha ${ }^{95}$ investigated the encapsulation of thymol in ethylcellulose or methylcellulose spheres. Wattanasatcha et al. showed that the MIC and minimum bactericidal concentration (MBC) for pure thymol and its nano-encapsulated formulation against $E$. coli and $S$. aureus were comparable. Unfortunately, pure thymol was more effective than nano-encapsulated thymol against $P$. aeruginosa.

Several studies have explored the use of grafted chitosan nanoparticles. ${ }^{63,65,96,97}$ Grafting of chitosan, a biopolymer with antibacterial properties, to nanoparticles confers a positive charge to the nanoparticle. This positive charge facilitates interactions between the nanoparticle and the negatively charged bacterial cell wall. A study conducted by $\mathrm{Chen}^{63}$ investigated formulations of eugenol-grafted and carvacrol-grafted chitosan nanoparticles. This study found antibacterial and antioxidant properties on E. coli and $S$. aureus for both the eugenol-grafted and carvacrolgrafted chitosan nanoparticles. In addition, the eugenolgrafted chitosan nanoparticles had a higher antibacterial efficiency than the carvacrol-grafted chitosan nanoparticles. Chitosan nanoparticles therefore seem effective against both $E$. coli and $S$. aureus. Jung ${ }^{97}$ also utilized eugenol grafted to chitosan to formulate a hydrogel with interesting antioxidant activity. Another study demonstrated the antibacterial activity of carvacrol-loaded chitosan nanoparticles against $S$. aureus, B. cereus and E. coli. ${ }^{65}$

Many studies have demonstrated the use of PLGA (poly(DL-lactide-co-glycolide)) for phenol encapsulation. Indeed, a study revealed the ability of carvacrol to combat biofilm formation using a polymeric film composed by biodegradable PLGA. The results showed that only $0.1 \%$ carvacrol was necessary to significantly decrease biofilm formation by $E$. coli and $S$. aureus. ${ }^{98}$ Another study, by Persico et al. ${ }^{99}$ demonstrated the antimicrobial activity of carvacrol nanoparticles dispersed in films based on lowdensity polyethylene (oregano-modified montmorillonite was used as the filler) against Brochothrix thermosphacta, L. innocua, Pseudomonas fragi, and Carnobacterium. Another study showed the antimicrobial activity of PLGA nanoparticles encapsulating eugenol and transcinnamaldehyde with poly(vinyl alcohol) (PVA) used as surfactant, ${ }^{100}$ which inhibited the growth of Salmonella (Gram-negative bacterium) and Listeria (Gram-positive bacterium). A study conducted by Ianniteli ${ }^{101}$ reported the production of carvacrol loaded PLGA nanocapsules. These nanocapsules are potential candidates for improving the effectiveness of antibacterial agents against biofilmassociated infections.

Shah $^{102}$ proposed a new process for encapsulating eugenol inside nanodispersions consisting of isolated protein (WPI) and maltodextrin (MD) combined in different ratios. Nanoparticles created with this process were evaluated to determine their antimicrobial efficacy on different bacteria such as E. coli and Listeria monocytogenes. ${ }^{41}$ The results indicated no improvement in effectiveness when the bacteria are in the presence of a culture medium (MBC and MIC $0.25 \mathrm{~g} / \mathrm{L}$ ). This system is more effective against $E$. coli (Gram-negative) than L. monocytogenes (Gram-positive). There is no difference in efficacy between pure eugenol and nanoencapsulated eugenol.

Eugenol nanofibers have been used as antimicrobial microemulsions against $S$. typhimurium and L. monocytogenes. This nanocarrier system was more effective against S. typhimurium than L. monocytogenes. ${ }^{103}$

Others products have been explored, such as metallic nanoparticles formulated with plant extracts. These metallic nanoparticles have been shown to have strong antibacterial activity. ${ }^{104-106}$ For example, the use of silver and gold nanoparticles combined with extracts of Mentha piperita plant was effective against $E$. coli and S. aureus. ${ }^{105}$

Many studies have demonstrated the efficacy of nanoparticles in murine models. For instance, a study demonstrated that nitric oxide nanoparticles accelerated the healing of Acinetobacter baumanni infected wounds in a murine 
model. ${ }^{107}$ Another study showed the synergistic effects of combining chitosan and silver nanoparticles to treat a burn infected with $P$. aeruginosa: the survival rates of mice were $64.3 \%$ with silver-chitosan versus $0 \%$ with untreated mice. ${ }^{108}$

\section{Novel Phenolic Compounds Delivery System}

Nanotechnologies have many advantages for encapsulating lipophilic actives such as phenols (Fig. 7), and encapsulated actives have an undeniable power against many MRBs. However, most of these vectors have many drawbacks, including a need for solvents or a significant energy demand for their manufacture. The use of solvents may promote the evaporation of phenols and/or alter their antibacterial activity. In light of these disadvantages, another type of nanoparticle, lipid nanocapsules (NCLs), may be suitable for the encapsulation of phenolic components. NCLs are composed of an oil core (e.g., triglyceride) for homogeneous distribution of the lipophilic active surrounded amphiphilic surfactants (e.g., polyethylene glycol). NCLs allow low complement activation. NCL preparation requires very little energy and no solvents. Moreover, the process is adaptable and may be conducted at a low temperature, avoiding degradation of phenols. In addition, antibiotics can be used in combination with phenols to decrease the effective dose of antibiotics on MRBs as well as the side effects of antibiotics. For instance, Fadli found synergies for 57 combinations between two EOs whose major component is carvacrol (Thymus marroccanus and Thymus broussonetii) and four antibiotics (ciprofloxacin, gentamicin, pristinamycin and cefixime). Carvacrol decreased the MIC of ciprofloxacin on Gram-negative bacteria by four-fold and the MIC of ciprofloxacin on Gram-positive bacteria by 8 - to 16 -fold. ${ }^{109}$

An interesting study showed synergies between silver nanoparticles using plant extracts with antibiotics against A. baumannii, P. aeruginosa and E. coli. An 11.8fold increase in the $E$. coli inhibition diameter around streptomycin was observed when the antibiotic combined with silver nanoparticles. ${ }^{110}$

\section{CONCLUSION}

The antibacterial effectiveness of phenols against Gramnegative or Gram-positive pathogenic bacteria is widely described in various studies. In light of the very specific behavior of EOs and their major components, encapsulation of EO components is an interesting treatment against MRB. Several studies underscore the success of encapsulation with different delivery system. These systems can be explored in combination with antibiotics in in vivo models.

Acknowledgment: The authors would like to acknowledge the Eydo Pharma company supported by the Association Nationale de la Recherche et de la Technologie, the bacteriology service of Angers University Hospital and INSERM (U1066 "Biomimetic Micro-nanomedicine").

\section{REFERENCES}

1. H. Nikaido, Multidrug resistance in bacteria. Annu. Rev. Biochem. 78, 119 (2009).

2. Enquête Nationale de Prévalence des infections nosocomiales et des traitements aux infetieux en établissement de santé, Institut de veille sanitaire (2012).

3. K. B. Kirkland, J. P. Briggs, S. L. Trivette, W. E. Wilkinson, and D. J. Sexton, The impact of surgical-site infections in the 1990s: Attributable mortality, excess length of hospitalization, and extra costs. Infect Control Hosp Epidemiol. 20, 725 (1999).

4. Decré, Acinetobacter baumannii and multiresistance: A successful adaptative model. Revue Francophone Des Laboratoire 2012, 43 (2012).

5. F. Martinez-Gutierrez, L. Boegli, A. Agostinho, E. M. Sanchez, H. Bach, F. Ruiz, and G. James, Anti-biofilm activity of silver nanoparticles against different microorganisms. Biofouling 29, 651 (2013).

6. D. Wei, W. Sun, W. Qian, Y. Ye, and X. Ma, The synthesis of chitosan-based silver nanoparticles and their antibacterial activity. Carbohydr Res. 344, 2375 (2009).

7. V. D. Badwaik, C. B. Willis, D. S. Pender, R. Paripelly, M. Shah, Y. A. Kherde, L. M. Vangala, M. S. Gonzalez, and R. Dakshinamurthy, Antibacterial gold nanoparticles-biomass assisted synthesis and characterization. J. Biomed. Nanotechnol. 9, 1716 (2013).

8. J. Bresee, K. E. Maier, A. E. Boncella, C. Melander, and D. L. Feldheim, Growth inhibition of Staphylococcus aureus by mixed monolayer gold nanoparticles. Small 7, 2027 (2011).

9. Y. Liu, L. He, A. Mustapha, H. Li, Z. Q. Hu, and M. Lin, Antibacterial activities of zinc oxide nanoparticles against Escherichia coli O157:H. J. Appl. Microbiol. 107, 1193 (2009).

10. S. T. Hojati, H. Alaghemand, F. Hamze, F. A. Babaki, R. RajabNia, M. B. Rezvani, M. Kaviani, and M. Atai, Antibacterial, physical and mechanical properties of flowable resin composites containing zinc oxide nanoparticles. Dent Mater. 29, 495 (2013).

11. L. R. Martinez, G. Han, M. Chacko, M. R. Mihu, M. Jacobson, P. Gialanella, A. J. Friedman, J. D. Nosanchuk, and J. M. Friedman, Antimicrobial and healing efficacy of sustained release nitric oxide nanoparticles against Staphylococcus aureus skin infection. J. Invest. Dermatol. 129, 2463 (2009).

12. E. M. Hetrick, J. H. Shin, N. A. Stasko, C. B. Johnson, D. A. Wespe, E. Holmuhamedov, and M. H. Schoenfisch, Bactericidal efficacy of nitric oxide-releasing silica nanoparticles. ACS Nano 2 , 235 (2008)

13. F. Bakkali, S. Averbeck, D. Averbeck, and M. Idaomar, Biological effects of essential oils-a review. Food Chem. Toxicol. 46, 446 (2008).

14. S. Burt, Essential oils: Their antibacterial properties and potential applications in foods-a review. Int. J. Food Microbiol. 94, 223 (2004).

15. K.-H. B. Bajpaia and S. C. Kangb, Control of Salmonella in foods by using essential oils: A review. Food Research International 45, 722 (2011).

16. H. R. D. D. E. Stevenson, Polyphenolic phytochemicals-just antioxidants or much more? Cellular and Molecular Life Sciences 64, 2900 (2007)

17. A. Ultee, M. H. Bennik, and R. Moezelaar, The phenolic hydroxyl group of carvacrol is essential for action against the food-borne pathogen Bacillus cereus. Appl. Environ. Microbiol. 68, 1561 (2002).

18. A. Ultee, E. P. Kets, M. Alberda, F. A. Hoekstra, and E. J. Smid, Adaptation of the food-borne pathogen Bacillus cereus to carvacrol. Arch. Microbiol. 174, 233 (2000). 
19. M. Vaara, Agents that increase the permeability of the outer membrane. Microbiol. Rev. 56, 395 (1992).

20. A. Tohidpour, M. Sattari, R. Omidbaigi, A. Yadegar, and J. Nazemi, Antibacterial effect of essential oils from two medicinal plants against Methicillin-resistant Staphylococcus aureus (MRSA). Phytomedicine 17, 142 (2010).

21. L. Fisher and D. North, Effectiveness of low-dose daptomycin in the treatment of vancomycin-resistant enterococcal urinary tract infections. Int. J. Antimicrob. Agents 33, 493 (2009).

22. S. Shin and J. H. Kim, In vitro inhibitory activities of essential oils from two Korean thymus species against antibiotic-resistant pathogens. Arch. Pharm. Res. 28, 897 (2005).

23. V. K. Bajpai, K. H. Baek, and S. C. Kang, Control of Salmonella in foods by using essential oils: A review. Food Research International 45, 722 (2012).

24. R. Di Pasqua, N. Hoskins, G. Betts, and G. Mauriello, Changes in membrane fatty acids composition of microbial cells induced by addiction of thymol, carvacrol, limonene, cinnamaldehyde, and eugenol in the growing media. J. Agric Food Chem. 54, 2745 (2006).

25. R. Garcia-Garcia, A. Lopez-Malo, and E. Palou, Bactericidal action of binary and ternary mixtures of carvacrol, thymol, and eugenol against Listeria innocua. J. Food Sci. 76, M95 (2011).

26. J. Xu, F. Zhou, B. P. Ji, R. S. Pei, and N. Xu, The antibacterial mechanism of carvacrol and thymol against Escherichia coli. Lett. Appl. Microbiol. 47, 174 (2008).

27. S. A. Burt and R. D. Reinders, Antibacterial activity of selected plant essential oils against Escherichia coli O157:H. Lett. Appl. Microbiol. 36, 162 (2003).

28. H. J. Dorman and S. G. Deans, Antimicrobial agents from plants: Antibacterial activity of plant volatile oils. Journal of Applied Microbiology 88, 308 (1999).

29. A. Rao, Y. Zhang, S. Muend, and R. Rao, Mechanism of antifungal activity of terpenoid phenols resembles calcium stress and inhibition of the TOR pathway. Antimicrob. Agents Chemother. 54, 5062 (2010).

30. M. Suutari and S. Laakso, Microbial fatty acids and thermal adaptation. Crit. Rev. Microbiol. 20, 285 (1994).

31. D. R. H. Keweloh and H.-J. Rehm, Increase of phenol tolerance of Escherichia coli by alterations of the fatty acid composition of the membrane lipids. Archives of Microbiolgy 157, 49 (1991).

32. M. Cristani, M. D’Arrigo, G. Mandalari, F. Castelli, M. G. Sarpietro, D. Micieli, V. Venuti, G. Bisignano, A. Saija, and D. Trombetta, Interaction of four monoterpenes contained in essential oils with model membranes: Implications for their antibacterial activity. J. Agric Food Chem. 55, 6300 (2007).

33. F. Dubois-Brissonnet, M. Naitali, A. A. Mafu, and R. Briandet, Induction of fatty acid composition modifications and tolerance to biocides in Salmonella enterica serovar Typhimurium by plantderived terpenes. Appl. Environ. Microbiol. 77, 906 (2010).

34. P. Falcone, B. Speranza, M. A. Del Nobile, M. R. Corbo, and M. Sinigaglia, A study on the antimicrobial activity of thymol intended as a natural preservative. J. Food Prot. 68, 1664 (2005).

35. S. Gaysinsky, T. M. Taylor, P. M. Davidson, B. D. Bruce, and J. Weiss, Antimicrobial efficacy of eugenol microemulsions in milk against Listeria monocytogenes and Escherichia coli O157:H. J. Food Prot. 70, 2631 (2007).

36. N. Terjung, M. Loffler, M. Gibis, J. Hinrichs, and J. Weiss, Influence of droplet size on the efficacy of oil-in-water emulsions loaded with phenolic antimicrobials. Food Funct. 3, 290 (2011).

37. D. E. J. J. P. Quinn, C. A. DiVincenzo, D. A. Lucks, and S. A Lerner, Emergence of resistance to imipenem during therapy for pseudomonas aeruginosa infections. The Journal of Infectious Diseases 154, 289 (1986).

38. F. J. Weber and J. A. de Bont, Adaptation mechanisms of microorganisms to the toxic effects of organic solvents on membranes. Biochim. Biophys. Acta 1286, 225 (1996).
39. S. A. Burt, R. van der Zee, A. P. Koets, A. M. de Graaff, F. van Knapen, W. Gaastra, H. P. Haagsman, and E. J. Veldhuizen, Carvacrol induces heat shock protein 60 and inhibits synthesis of flagellin in Escherichia coli O157:H7. Appl. Environ. Microbiol. 73, 4484 (2007).

40. S. P. N. R. J. W. Lambert, P. J. Coote, and G.-J. E. Nychas, A study of the minimum inhibitory concentration and mode of action of oregano essential oil, thymol and carvacrol. Journal of Applied Microbiology 91, 453 (2001).

41. H.-L. A. Helander, K. Latva-Kala, T. Mattila-Sandholm, I. Pol, E. J. Smid, L. G. M. Gorris, and A. von Wright, Characterization of the action of selected essential oil components on gram-negative bacteria. J. Agric. Food. Chem. 46, 3590 (1998).

42. D. Trombetta, F. Castelli, M. G. Sarpietro, V. Venuti, M. Cristani, C. Daniele, A. Saija, G. Mazzanti, and G. Bisignano, Mechanisms of antibacterial action of three monoterpenes. Antimicrob. Agents Chemother. 49, 2474 (2005).

43. I. Rasooli, M. B. Rezaei, and A. Allameh, Ultrastructural studies on antimicrobial efficacy of thyme essential oils on Listeria monocytogenes. Int. J. Infect. Dis. 10, 236 (2006).

44. B. J. G. Thoroski and C. Biliaderis, Eugenol induced inhibition of extracellular enzyme production by bacillus cereus. J. Food Prot. 52, 399 (1989).

45. A. O. Gill and R. A. Holley, Disruption of Escherichia coli, Listeria monocytogenes and Lactobacillus sakei cellular membranes by plant oil aromatics. Int. J. Food Microbiol. 108, 1 (2006).

46. A. Ben Arfa, S. Combes, L. Preziosi-Belloy, N. Gontard, and P. Chalier, Antimicrobial activity of carvacrol related to its chemical structure. Lett. Appl. Microbiol. 43, 149 (2006).

47. C. N. Wendakoon and M. Sakaguchi, Inhibition of amino acid decarboxylase activity of enterobacter aerogenes by active components in spices. J. Food Prot. 58, 280 (1995).

48. A. O. Gill and R. A. Holley, Mechanisms of bactericidal action of cinnamaldehyde against Listeria monocytogenes and of eugenol against L. monocytogenes and Lactobacillus sakei. Appl. Environ. Microbiol. 70, 5750 (2004).

49. S. E. Walsh, J. Y. Maillard, A. D. Russell, C. E. Catrenich, D. L. Charbonneau, and R. G. Bartolo, Activity and mechanisms of action of selected biocidal agents on gram-positive and -negative bacteria. J. Appl. Microbiol. 94, 240 (2003).

50. S. Y. Wong, I. R. Grant, M. Friedman, C. T. Elliott, and C. Situ, Antibacterial activities of naturally occurring compounds against Mycobacterium avium subsp. paratuberculosis. Appl. Environ. Microbiol. 74, 5986 (2008).

51. Y. J. Fu, Y. G. Zu, L. Y. Chen, X. G. Shi, Z. Wang, S. Sun, and T. Efferth, Antimicrobial activity of clove and rosemary essential oils alone and in combination. Phytotherapy Research 21, 989 (2007).

52. J. Gutierrez, C. Barry-Ryan, and R. Bourke, The antimicrobial efficacy of plant essential oil combinations and interactions with food ingredients. International Journal of Food Microbiology 124, 91 (2008).

53. N. A. Olasupo, D. J. Fitzgerald, M. J. Gasson, and A. Narbad, Activity of natural antimicrobial compounds against Escherichia coli and Salmonella enterica serovar Typhimurium. Lett. Appl. Microbiol. 37, 448 (2003).

54. R. S. Pei, F. Zhou, B. P. Ji, and J. Xu, Evaluation of combined antibacterial effects of eugenol, cinnamaldehyde, thymol, and carvacrol against E. coli with an improved method. J. Food Sci. 74, M379 (2009).

55. P. E. A. Santiesteban-López and A. López-Malo, Susceptibility of food-borne bacteria to binary combinations of antimicrobials at selected aw and pH. Journal of Applied Microbiology 102, 486 (2006).

56. L.-M. A. R. García-García and E. Palou, Bactericidal action of binary and ternary mixtures of carvacro, thymol, and eugenol against of Listeria innocua. J. Food Sci. 76, M95 (2011). 
57. S. A. I. M. M. Tajkarimi and D. O. Cliver, Antimicrobial herb and spice compounds in food. Food Control 21, 1199 (2010).

58. J. M. J. Michiels, D. Fremaut, S. De Smet, and N. Dierick, In vitro dose-response of carvacrol, thymol, eugenol and transcinnamaldehyde and interaction of combinations for the antimicrobial activity against the pig gut flora. Livestock Science 109, 157 (2007).

59. Y. Shoji and H. Nakashima, Nutraceutics and delivery systems. J. Drug Target 12, 385 (2004).

60. C. Del Toro-Sanchez, J. F. Ayala-Zavala, L. Machi, H. Santacruz, M. A. Villegas-Ochoa, E. Alvarez-Parrilla, and G. A. GonzalezAguilar, Controlled release of antifungal volatiles of thyme essential oil from beta-cyclodextrin capsules. Journal of Inclusion Phenomena and Macrocyclic Chemistry 67, 431 (2010).

61. Y. Chang, L. McLandsborough, and D. J. McClements, Physical properties and antimicrobial efficacy of thyme oil nanoemulsions: Influence of ripening inhibitors. J. Agric Food. Chem. 60, 12056 (2012).

62. H. M. C. Marques, A review on cyclodextrin encapsulation of essential oils and volatiles. Flavour and Fragrance Journal 25, 313 (2010).

63. F. Chen, Z. L. Shi, K. G. Neoh, and E. T. Kang, Antioxidant and antibacterial activities of eugenol and carvacrol-grafted chitosan nanoparticles. Biotechnol. Bioeng. 104, 30 (2009).

64. G. C. E. H. Laura and T. T. Matthew, Characterization of betacyclodextrin inclusion complexes containing essential oils (transcinnamaldehyde, eugenol, cinnamon bark, and clove bud extracts) for antimicrobial delivery applications. LWT-Food Science and Technology 51, 86 (2013).

65. L. Keawchaoon and R. Yoksan, Preparation, characterization and in vitro release study of carvacrol-loaded chitosan nanoparticles. Colloids Surf. B Biointerfaces 84, 163 (2011).

66. A. Vonarbourg, C. Passirani, P. Saulnier, P. Simard, J. C. Leroux, and J. P. Benoit, Evaluation of pegylated lipid nanocapsules versus complement system activation and macrophage uptake. J. Biomed. Mater. Res. A 78, 620 (2006).

67. M. A. Donsì, M. Sessa, and G. Ferrari,, Nanoencapsulation of essential oils to enhance their antimicrobial activity in foods. Food Science and Technologies 44, 1908 (2011).

68. R. Baranauskiené, P. R. Venskutonis, K. Dewettinck, and R. Verhé, Properties of oregano (Origanum vulgare L.), citronella (Cymbopogon nardus G.) and marjoram (Majorana hortensis L.) flavors encapsulated into milk protein-based matrices. Food Research International 39, 413 (2006).

69. C. I. Beristain, H. S. Garcćia, and E. J. Vernon-Carter, Spray-dried encapsulation of cardamom (elettaria cardamomum) essential oil with mesquite (prosopis juliflora). Gum Food Science and Technology 24, 398 (2001).

70. G. M. Glenn, A. P. Klamczynski, D. F. Woods, B. Chiou, W. J. Orts, and S. H. Imam, Encapsulation of plant oils in porous starch microspheres. J. Agric Food Chem. 58, 4180 (2010).

71. E. Gavini, V. Sanna, R. Sharma, C. Juliano, M. Usai, M. Marchetti, J. Karlsen, and P. Giunchedi, Solid lipid microparticles (SLM) containing juniper oil as anti-acne topical carriers: Preliminary studies. Pharm. Dev. Technol. 10, 479 (2005).

72. B. Heurtault, P. Saulnier, B. Pech, J. E. Proust, and J. P. Benoit, A novel phase inversion-based process for the preparation of lipid nanocarriers. Pharm. Res. 19, 875 (2002).

73. G. G. K. Schubert and F. Lisdat, Bilirubin oxidase bound to multiwalled carbon nanotube-modified gold. Electrochim. Acta 54, 3033 (2009).

74. T. J. Wooster, M. Golding, and P. Sanguansri, Impact of oil type on nanoemulsion formation and Ostwald ripening stability. Langmuir 24, 12758 (2008).

75. K. Ziani, Y. Chang, L. McLandsborough, and D. J. McClements, Influence of surfactant charge on antimicrobial efficacy of surfactant-stabilized thyme oil nanoemulsions. J. Agric Food Chem. 59, 6247 (2011).

76. A. S. Pedro, E. Cabral-Albuquerque, D. Ferreira, and B. Sarmento, Chitosan: An option for development of essential oil delivery systems for oral cavity care? Carbohydr. Polym. 76, 501 (2009).

77. Q. Wang, J. Gong, X. Huang, H. Yu, and F. Xue, In vitro evaluation of the activity of microencapsulated carvacrol against Escherichia coli with K88 pili. Journal of Applied Microbioly 107, 1781 (2009).

78. A. S. Ulrich, Biophysical aspects of using liposomes as delivery vehicles. Biosci Rep. 22, 129 (2002).

79. G. O. C. C. Liolios, S. Lalas, J. Tsaknis, and I. Chinou, Liposomal incorporation of carvacrol and thymol isolated from the essential oil of Origanum dictamnus L. and in vitro antimicrobial activity. Food Chem. 112, 77 (2008).

80. Gortzi, S. Lalas, I. Chinou, and J. Tsaknis, Reevaluation of bioactivity and antioxidant activity of Myrtus communis extract before and after encapsulation in liposomes. European Food Research and Technology 226, 583 (2008).

81. C. Sinico, A. De Logu, F. Lai, D. Valenti, M. Manconi, G. Loy, L. Bonsignore, and A. M. Fadda, Liposomal incorporation of Artemisia arborescens L. essential oil and in vitro antiviral activity. Eur. J. Pharm. Biopharm. 59, 161 (2005).

82. R. Aeschbach, J. Loliger, B. C. Scott, A. Murcia, J. Butler, B. Halliwell, and O. I. Aruoma, Antioxidant actions of thymol, carvacrol, 6-gingerol, zingerone and hydroxytyrosol. Food Chem. Toxicol. 32, 31 (1994).

83. G. M. V. Lagouri and O. Gurbuz, In vitro antioxidant/free radical scavenging and antibacterial properties of endemic oregano and thyme extracts from Greece. Food Science and Biotechnology 20, 1487 (2011).

84. J. Chang and D. Betbeder, Targeting drug delivery to the brain via transferrin anchored nanoparticles. Nanomedecine and the Nervous System (2012).

85. S. Gaysinsky, P. M. Davidson, B. D. Bruce, and J. Weiss, Growth inhibition of Escherichia coli O157:H7 and Listeria monocytogenes by carvacrol and eugenol encapsulated in surfactant micelles. J. Food Prot. 68, 2559 (2005).

86. S. Gaysinsky, P. M. Davidson, B. D. Bruce, and J. Weiss, Stability and antimicrobial efficiency of eugenol encapsulated in surfactant micelles as affected by temperature and pH. J. Food Prot. 68, 1359 (2005).

87. S. Gaysinsky, P. M. Davidson, D. J. McClements, and J. Weiss, Formulation and characterization of phytophenol-carrying antimicrobial microemulsions. Food Biophysics 3, 54 (2007).

88. D. Perez-Conesa, J. Cao, L. Chen, L. McLandsborough, and J. Weiss, Inactivation of Listeria monocytogenes and Escherichia coli O157:H7 biofilms by micelle-encapsulated eugenol and carvacrol. J. Food Prot. 74, 55 (2011).

89. D. Perez-Conesa, L. McLandsborough, and J. Weiss, Inhibition and inactivation of Listeria monocytogenes and Escherichia coli O157:H7 colony biofilms by micellar-encapsulated eugenol and carvacrol. J. Food Prot. 69, 2947 (2006).

90. S. F. Hamed, Z. Sadek, and A. Edris, Antioxidant and antimicrobial activities of clove bud essential oil and eugenol nanoparticles in alcohol-free microemulsion. Journal of Oleo Science 61, 641 (2012).

91. N. Parris, P. H. Cooke, and K. B. Hicks, Encapsulation of essential oils in zein nanospherical particles. J. Agric Food Chem. 53, 4788 (2005).

92. K. K. Li, S. W. Yin, X. Q. Yang, C. H. Tang, and Z. H. Wei, Fabrication and characterization of novel antimicrobial films derived from thymol-loaded zein-sodium caseinate (SC) nanoparticles. J. Agric. Food. Chem. 60, 11592 (2012). 
93. Y. P. Wu, Y. G. Luo, and Q. Wang, Antioxidant and antimicrobia properties of essential oils encapsulated in zein nanoparticles prepared by liquid-liquid dispersion method. Lwt-Food Science and Technology 48, 283 (2012).

94. G. Kavoosi, S. M. M. Dadfar, and A. M. Purfard, Mechanical, physical, antioxidant, and antimicrobial properties of gelatin films incorporated with thymol for potential use as nano wound dressing. J. Food Sci. 78, E244 (2013).

95. A. Wattanasatcha, S. Rengpipat, and S. Wanichwecharungruang, Thymol nanospheres as an effective anti-bacterial agent. Int. J. Pharm. 434, 360 (2012).

96. D. Altiok, E. Altiok, and F. Tihminlioglu, Physical, antibacterial and antioxidant properties of chitosan films incorporated with thyme oil for potential wound healing applications. J. Mater. Sci. Mater. Med. 21, 2227 (2010).

97. B. O. Jung, S. J. Chung, and S. B. Lee, Preparation and characterization of eugenol-grafted chitosan hydrogels and their antioxidant activities. J. Appl. Polym. Sci. 99, 3500 (2006).

98. K. R. Zodrow, J. D. Schiffman, and M. Elimelech, Biodegradable polymer (PLGA) coatings featuring cinnamaldehyde and carvacrol mitigate biofilm formation. Langmuir 28, 13993 (2012).

99. P. Persico, V. Ambrogi, C. Carfagna, P. Cerruti, I. Ferrocino, and G. Mauriello, Nanocomposite polymer films containing carvacrol for antimicrobial active packaging. Polym. Eng. Sci. 49, 1447 (2009).

100. C. Gomes, R. G. Moreira, and E. Castell-Perez, Poly(DLlactide-co-glycolide) (PLGA) nanoparticles with entrapped trans-cinnamaldehyde and eugenol for antimicrobial delivery applications. J. Food Sci. 76, N16 (2011).

101. A. Iannitelli, R. Grande, A. Di Stefano, M. Di Giulio, P. Sozio, L. J. Bessa, S. Laserra, C. Paolini, F. Protasi, and L. Cellini, Potential antibacterial activity of carvacrol-loaded poly(DL-lactideco-glycolide) (PLGA) nanoparticles against microbial biofilm. International Journal of Molecular Sciences 12, 5039 (2011).

102. B. Shah, P. M. Davidson, and Q. Zhong, Nanodispersed eugenol has improved antimicrobial activity against Escherichia coli O157:H7 and Listeria monocytogenes in bovine milk. Int. J. Food Microbiol. 161, 53 (2012).
103. C. Kriegel, K. M. Kit, D. J. McClements, and J. Weiss, Nanofibers as carrier systems for antimicrobial microemulsions. II. Release characteristics and antimicrobial activity. J. Appl. Polym. Sci. 118, 2859 (2010).

104. J. L. Huang, Q. B. Li, D. H. Sun, Y. H. Lu, Y. B. Su, X. Yang, H. X. Wang, Y. P. Wang, W. Y. Shao, N. He, J. Q. Hong, and C. X. Chen, Biosynthesis of silver and gold nanoparticles by novel sundried cinnamomum camphora leaf. Nanotechnology 18 (2007).

105. D. Mubarak Ali, N. Thajuddin, K. Jeganathan, and M. Gunasekaran, Plant extract mediated synthesis of silver and gold nanoparticles and its antibacterial activity against clinically isolated pathogens. Colloids Surf. B Biointerfaces 85, 360 (2011).

106. G. Singhal, R. Bhavesh, K. Kasariya, A. R. Sharma, and R. P. Singh, Biosynthesis of silver nanoparticles using Ocimum sanctum (Tulsi) leaf extract and screening its antimicrobial activity. J. Nanopart. Res. 13, 2981 (2011).

107. M. R. Mihu, U. Sandkovsky, G. Han, J. M. Friedman, J. D. Nosanchuk, and L. R. Martinez, The use of nitric oxide releasing nanoparticles as a treatment against Acinetobacter baumannii in wound infections. Virulence 1, 62 (2010).

108. L. Huang, T. Dai, Y. Xuan, G. P. Tegos, and M. R. Hamblin, Synergistic combination of chitosan acetate with nanoparticle silver as a topical antimicrobial: Efficacy against bacterial burn infections. Antimicrob. Agents Chemother 55, 3432 (2011)

109. S. A. M. Fadli, S. Sayadi, J. Chevalier, N.-E. Mezrioui, J.-M. Pagès, and L. Hassani, Antibacterial activity of thymus maroccanus and thymus broussonetii essential oils against nosocomial infection-bacteria and their synergistic potential with antibiotics. Phytomedecine 19, 464 (2011).

110. S. Ghosh, S. Patil, M. Ahire, R. Kitture, S. Kale, K. Pardesi, S. S. Cameotra, J. Bellare, D. D. Dhavale, A. Jabgunde, and B. A. Chopade, Synthesis of silver nanoparticles using dioscorea bulbifera tuber extract and evaluation of its synergistic potential in combination with antimicrobial agents. Int. J. Nanomedicine 7, 483 (2012).

111. Y. Hu, Y. M. Du, X. Y. Wang, and T. Feng, Self-aggregation of water-soluble chitosan and solubilization of thymol as an antimicrobial agent. Journal of Biomedical Materials Research Part A 90A, 874 (2009). 